\title{
Premature Mortality Among People with Mental Illness: Advocacy in Academic Psychiatry
}

\author{
Laura Weiss Roberts ${ }^{1}$ - Alan K. Louie ${ }^{1}$ - Anthony P. S. Guerrero ${ }^{2} \cdot$ Richard Balon $^{3}$ • \\ Eugene V. Beresin ${ }^{4} \cdot$ Adam Brenner $^{5} \cdot$ John Coverdale $^{6}$
}

Received: 12 May 2017 / Accepted: 17 May 2017 /Published online: 5 June 2017

(C) Academic Psychiatry 2017

Mental illness accounts for one third of all years lived with disability throughout the world, and by 2020 , depression will be the second leading cause of global disability [1-3]. Despite its tragic position as the leading cause of global disease burden, mental illness is underappreciated for its impact on overall population health [4]. For instance, funding from the National Institutes of Health (NIH) for infectious disease and cancer far outstrips the funding for mental illness [5]. Perhaps this is due to the fact that cancer and infectious disease are seen as life threatening and leading to premature mortality more often than mental illness. While public descriptors of people with mental disorders have included "in need of help," "unpredictable," "violent," and "dangerous" [6], mention of shortened life span or risk of dying is absent. These omissions imply a poorly informed public; major mental illness is now clearly known to be associated with premature mortality and in this sense should be considered potentially fatal.

Earlier this decade, Druss et al. [7] published a 17-year follow-up study of US data and found that people with mental disorders died 8 years earlier on average than people without these disorders. Similarly, in 2006, the National Association of State Mental Health Program Directors [8] issued a report

Laura Weiss Roberts

RobertsL@stanford.edu

Stanford University, Stanford, CA, USA

2 University of Hawai'i John A. Burns School of Medicine, Honolulu, HI, USA

3 Wayne State University, Detroit, MI, USA

4 Harvard Medical School, Boston, MA, USA

5 University of Texas Southwestern Medical Center, Dallas, TX, USA

6 Baylor College of Medicine, Houston, TX, USA concluding that people with severe mental illness died 25 years earlier on average than the general population. Updated information from the World Health Organization [9] states that the life expectancy of people with severe mental disorders is decreased by 10 to 25 years. Nevertheless, has the public's perception regarding premature mortality in mental illness changed over the last 10 years?

Undoubtedly the cause of premature mortality is multifactorial, including poor access to care, stigma preventing the seeking of care, reduced insurance reimbursement for mental illnesses, insufficient workforce of mental health clinicians, inadequate funding for research on mental illnesses, and more. In this editorial, we review some of the potential contributors to premature mortality in individuals with major mental disorders and the barriers that persist in preventing our society from addressing the social injustice experienced by these people as a health disparities population. Finally, we define an advocacy role for academic psychiatry in lengthening the lives and improving the health outcomes of people living with and at risk for mental illness.

\section{Factors Associated with Premature Mortality in People with Mental Illness}

Suicide is perhaps the most widely recognized contributor to premature mortality in the context of mental illness. Suicide is the tenth leading cause of death overall in the USA according to recent data from the Center for Disease Control and Prevention, with 42,773 suicides occurring in 2014 [10]. Furthermore, suicide is the second leading cause of death in children ages 10-14 years [10] and it is the second leading cause of death in veterans, mostly associated with posttraumatic stress disorder [11]. Such findings are consistent with a large, somewhat older population-based study $(n=72,208)$ of 
causes of death over a 20-year period, which revealed that one quarter of individuals with mental illness died by homicide, suicide, or other unnatural causes [12].

Troublingly, the rate of people dying from suicide has been increasing in the USA. In 2014, in what has been called an epidemic, the rate of people dying from suicide in the USA was higher than it had been in 30 years. Although the rate had been declining since the 1980s, it has been rising since 1999, and has been rising especially fast since 2006. Figure 1 is a graph of data from the National Center for Health Statistics (NCHS) that compares the number of suicides per 100,000 individuals in 1999 versus 2014, parsed out by age and gender [13]. The rates of suicide have increased in all age groups under 75 years, and the increase is especially true for the 45to 65 -year-old cohort. The total number of suicides remains much greater in men than in women, but the greatest percentage increase was in women in this age group.

Substance use disorders are another recognized contributor to premature mortality for people living with mental illness [14]. Substance use disorders are among the most common type of psychiatric disorder, along with mood and anxiety disorders. Premature mortality associated with substance use disorders has always existed, but it has gained recent notoriety in the USA due to an epidemic of overdoses from prescription opioids and heroin. From 2002 to 2015, the number of deaths from opioid drugs, including heroin and illegal-opioid synthetics, increased by $280 \%$ according to NCHS data [15]. Many cases appear to involve the treatment of pain syndromes with prescription opioids, which are then complicated by addiction. Some people turn to heroin as a less expensive way to continue the opioid addiction. The overdose rate for heroin, when split from other opioid drugs, has increased $620 \%$ according to the NCHS data between 2002 and 2015 [15].
Of note, the recent US suicide and opioid overdose epidemics are of a large enough magnitude that they have been considered as the cause of a remarkable rise in the all-cause mortality figure for the 45- to 54-year-old population [16]. This finding was observed mainly in non-Hispanic whites in the USA and contrasts with other industrialized nations. Mortality rates have been dropping consistently in all age groups in the USA, so this rise in mortality is a countertrend starting in 1998. This study implicated suicides, drug and alcohol poisonings, and cirrhosis and chronic diseases of the liver as the driving factors behind the increase in mortality. The increase parallels the current suicide epidemic. The increase in drug poisoning has been attributed to the opioid epidemic because a high percentage of the drug overdoses are due to opioids. Many of the liver disorders are thought to be secondary to alcohol misuse.

Another substance use disorder is tobacco addiction, which is one of the major causes of premature mortality in people with and without psychiatric disorders [17]. Adults with mental illness and/or substance use disorder are disproportionately at risk for premature mortality from tobacco use because a higher percentage of these individuals smoke, and they often smoke more cigarettes compared to those without these conditions [18]. Adults with mental illness and/or substance use disorders smoke nearly $40 \%$ of all cigarettes on the market, according to the 2009 to 2011 National Survey on Drug Use and Health [19], sponsored by the Substance Abuse and Mental Health Services Administration. In fact, some evidence indicates that tobacco companies attempt to market cigarettes to people with mental illness [20]. Additionally, the mental health profession has not made smoking cessation a high priority in treatment, apparently due to several myths, including, for instance, that those with mental illness do not
Fig. 1 Adapted from Curtin SC, Warner M, Hedegaard H. Increase in suicide in the United States, 1999-2014. NCHS data brief, no 241. Hyattsville, MD: National Center for Health Statistics. 2016. Available at: https://www.cdc. gov/nchs/products/databriefs/ db241.htm. Accessed April 26, 2017

\section{Suicides per 100,000 Persons by Age and Gender, in 1999} and 2014

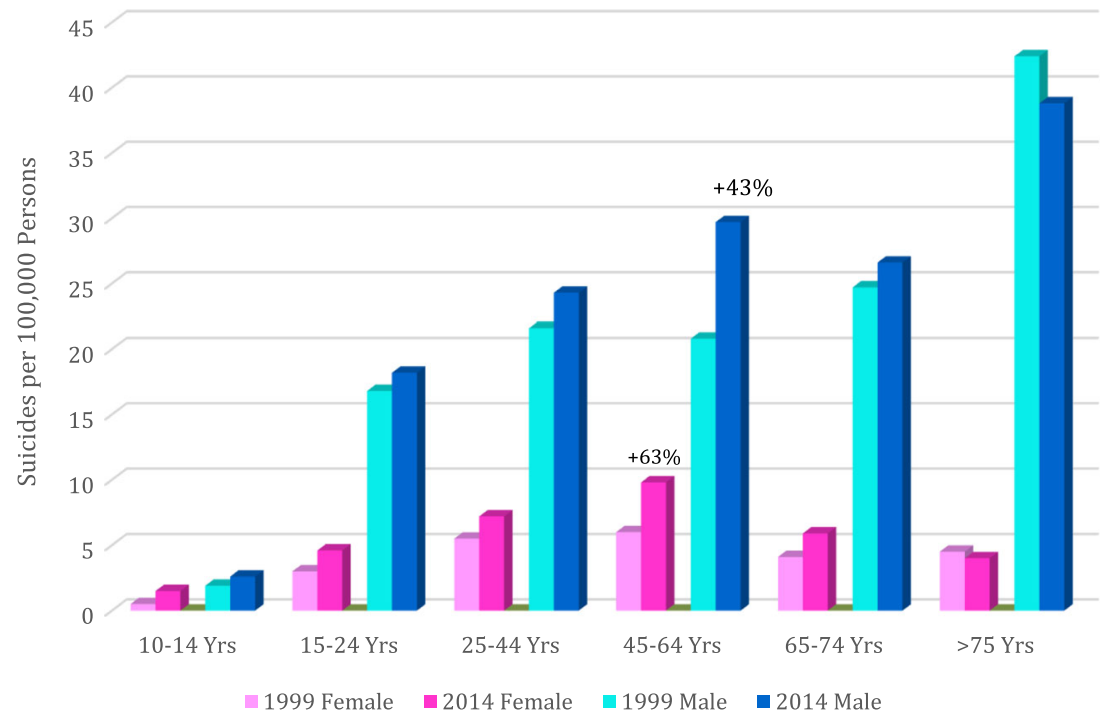


desire to stop smoking, are not able to stop, or will have more symptoms without the use of tobacco [21].

In addition to premature mortality directly resulting from symptomatology of psychiatric disorders (e.g., suicide, overdose), a large portion of premature mortality is secondary to comorbid medical diagnoses. In other words, people with mental illnesses develop and die from many medical conditions earlier than the general population. Druss et al. [7] found that "medical causes" were responsible for $95 \%$ of premature mortality of people with mental disorders, as opposed to unnatural causes. Cardiovascular diseases are especially prominent as a cause of death in people with major mental disorders [22]. Furthermore, the adverse effects of psychotropic medications including, for example, metabolic syndrome or sudden death associated with cardiac arrhythmias are associated with a reduced life span $[23,24]$. Additionally, those with severe mental illness have higher rates of type II diabetes, respiratory diseases like pneumonia, and infections including tuberculosis, HIV, and hepatitis [25]. Increased medical morbidity is, in part, caused by underdiagnosis and undertreatment of medical conditions in people with mental illness [25].

Environmental influences, including violence, homicide, victimization, and incarceration, are also important factors and/or mediators of premature mortality. Gun fatalities have a small influence on premature mortality in patients with mental disorders [26]. Nevertheless, homicide affects individuals with any mental illness at a rate 2.5 to 5 times greater than that of the general population $[27,28]$. Individuals with cooccurring mental illness and substance use disorders are victims of homicide at a rate nine times greater than that of the general population [27]. Incarceration also is a risk factor for premature mortality [29], and 45-64\% of adults incarcerated for a wide range of offenses are reported to have psychiatric disorders [30].

Poverty, in general, and lack of health care access are tremendous social determinants of premature mortality [31]. Many individuals with serious mental illness experience homelessness and socioeconomic decline because of the impairments specifically associated with their health conditions [32]. Less severe yet still chronic mental illnesses contribute to absenteeism and loss of employment [33]. As a consequence, people living with mental illness are far more likely to be uninsured or marginally insured than healthy or physically ill individuals [34], likely contributing to the observation that three quarters of premature mortality of individuals with mental illness are attributable to other health conditions that are often treatable [35].

Youth may be especially vulnerable to the life-shortening sequelae of untreated mental health conditions in themselves and in their parents. Individual and family mental illnesses factor prominently in the top three causes of youth mortality: unintentional injuries, suicide, and homicide [10]. Parents with depression are less likely to adequately safety-proof the home and more likely to use harsh discipline [36]. Early detection and intervention for mental health concerns are recognized as cornerstones of effective violence and suicide prevention in childhood and adolescence. Furthermore, toxic stress-potentially, both a cause and an effect of childhood and family mental illness - may adversely affect brain development through modification of the genome, which in turn influences long-term health and longevity in children [37].

\section{Barriers to Recognition}

Premature mortality associated with mental illness does not receive much recognition in society or in the medical literature. The reasons for this underrepresentation are familiar and multiple-we will offer just a few immediate examples. Mental illness research is not well funded relative to its status as the leading cause of disease burden [2-4]. Similarly, fewer scientists and clinicians work in this area [38] and considerable shortages exist in the number of mental health professionals in most communities throughout the world [39].

Stigma [40] and negative media bias [41] have been identified as factors that contribute to the relative neglect of mental illness in the literature. Stigma subverts funding of research and systems of care and the willingness of the mentally ill to seek care. Additionally, the stigma of mental illness is rampant throughout the world in virtually all cultural groups, including doctors and healthcare workers [42]. Stigma includes poor understanding of the signs and symptoms of mental illness, taboos associated with individuals expressing psychiatric symptoms, and individuals not receiving help for fear of retribution, shame, and retaliation.

The nature of mental illness is such that it may interfere with self-advocacy. Unlike other health conditions, mental illness has few advocates beyond the people who are living with these devastating conditions and their family members. Family members may be ill themselves or carrying some of the burden of illness of their loved ones, which makes doing more on a broad or public scale difficult. Moreover, mental health clinicians are marginalized and may feel stigmatized within the health profession, limiting the likelihood and impact of effective advocacy [43].

\section{The Role of Academic Psychiatry}

Academic psychiatry can do much to address the tragedy of health disparities among people living with mental illness by studying these issues, by elevating them in the public dialog, and by training medical students, residents, and fellows to provide astute mental health care. As leaders in academic medicine, academic psychiatrists can work together to 
advocate for positive steps to be taken in order to improve the health and longevity of people living with mental illness.

Through education and advocacy, academic psychiatrists can improve standards of care to include more comprehensive, integrated, and robust care for mental illness and other medical conditions with a focus on prevention, treatment, resilience, and recovery. Academic psychiatry has an important role in educating other fields of medicine and other groups throughout society about the determinants of disability and premature mortality associated with mental disorders. Furthermore, academic psychiatrists should advocate for greater efforts in undergraduate medical education and perhaps even mandated efforts in graduate medical education in the diagnosis and treatment of psychiatric disorders and their comorbid medical conditions.

As a field, psychiatry's efforts to provide sound public education about the nature, presentation, course, and treatment of psychiatric disorders have been insufficient. Education is seriously lacking among professionals who encounter mental illness daily, including teachers, coaches, clergy, law enforcement officials, and attorneys. Public education is inadequate on the signs and symptoms of psychiatric disorders, the ways in which disorders may be prevented, and the usefulness of early intervention. Addressing this education deficit will lessen the stigma associated with psychiatric disorders and help health outcomes by providing information on how to navigate the mental health system in schools, the community, and the healthcare sector. Public education may enable a wide range of people to seek early intervention and/or prevention efforts.

Moreover, investment is needed in clinical learning environments in the continuum of clinical services and supporting infrastructure and in the thorough integration of psychiatric and medical services. In this regard, academic psychiatrists can also work to improve access to mental health care. Of note, $17 \%$ of adults with a mental illness remain uninsured, down some from 19\% in 2011 before the Affordable Care Act [44]. Separate from insurance coverage, $56 \%$ of people with mental illness reportedly had received no treatment in the previous year, and $20 \%$ reported unmet treatment needs [44]. With potential changes in health policy associated with changes in federal administration, the likelihood of increased numbers of uninsured mentally ill individuals is great. President Obama's 2017 budget provided for $\$ 500$ million in new investments to increase access to mental health care [45]. At the time of this writing, the status of these funds is unclear.

Academic psychiatrists can also improve efforts to prevent mental health issues and to identify and intervene with such issues early. Half of all lifetime cases of mental illness begin by age 14 years; three quarters have begun by age 24 years [46]. The median delay in getting treatment is nearly a decade; the longest delays are 20-23 years [47]. Interventions to speed initial treatment contact are likely to reduce the burdens and hazards of untreated mental disorders. Furthermore, prevention is a key in decreasing the risks of many chronic psychiatric conditions. Interventions aimed at prevention or early treatment need to focus on youth. Trainees should gain experience in screening in schools and in primary care settings using the Pediatric Symptom Checklist; Screening, Brief Intervention, and Referral to Treatment (SBIRT); and other reliable and valid means of early assessment of youth at risk.

Academic psychiatrists can engage with governmental leaders to strengthen understanding of the true impact of mental illness and the need for discovery and innovation. Investment in science is needed to better understand the relationship between mental illness and early mortality and to discover the most effective methods to mitigate the multiple effects of mental illness on quality and length of life. The number and scope of truly tested interventions in individuals with major mental disorders are limited, and many interventions focus on a limited number of risk factors [48]. The National Institute of Mental Health's Research Domain Criteria initiative [49] holds the promise of new approaches to elucidate the mechanisms that link stressors to pathologic brain development. Equally important, however, is that funding be available for trials of biopsychosocial interventions to prevent, ameliorate, and reverse the impact of such stress.

Academic psychiatrists need to educate their trainees to help empower people living with mental illness through employment and housing. A helpful reference is the Employment and Mental Illness report and recommendations from the National Alliance on Mental Illness [50]. It is sobering to note from the report that employment of individuals with mental illness declined from $23 \%$ in 2003 to $18 \%$ in 2012. Furthermore, in 2012, fewer than $2 \%$ of individuals who served in state mental health systems received supported employment services [50]. Through their role modeling, academic psychiatrists need to strengthen their trainees' participation in organized advocacy and education for community stakeholders-including police, health systems, insurers, businesses, and the media - and convey the overall values of compassion and common decency (see [51] for examples of excellent resources).

Along those lines, academic psychiatrists need to continue their work in growing the future workforce, particularly in view of the fact that nearly $60 \%$ of active psychiatrists are 55 years or older and the percent change in number of active psychiatrists between 2010 and 2015 was $-1.4 \%$ [52]. Expanding the workforce will require funding to create more psychiatry residency slots and salary support for the faculty needed to provide supervision and teaching. While the current political climate may not present the most welcoming environment for such advocacy, academic psychiatrists are uniquely positioned to provide an evidence-based, nonideological approach and should consistently emphasize that the burden of suffering and mental illness on society is severe 
and that training an adequate supply of psychiatrists is far more cost effective than the alternative. Additionally, academic psychiatrists can advocate for funding mechanisms, such as loan repayment, that can incentivize psychiatry residency graduates to work in public psychiatry or in integrated care settings, where they might have the greatest impact on the early mortality associated with serious mental illness.

\section{Stepping Forward to Address Disparities}

Individuals with major mental disorders are potentially vulnerable along biological, psychological, and social dimensions, and they may have complex and multiple comorbid medical conditions and diseases, fragile social circumstances, and other co-occurring conditions that contribute to premature mortality. Academic psychiatrists should teach about the relevant contributory factors and the research that sheds light on how to reduce premature mortality across cultures and settings. Academic psychiatrists must strongly advocate for their patients and address the vulnerabilities that contribute to their suffering and early death. Academic psychiatrists need to address the gap between what they know may work and what is done to prevent premature mortality and they need to continue to evaluate the effectiveness of these interventions. We recognize that this work is a far-reaching public health challenge that will require highly coordinated, integrated, multicomponent responses at local and national levels.

It was only in the past century when, in certain parts of the USA, patients with another heavily stigmatized and commonly misunderstood illness-Hansen's diseasewere sent to isolation colonies [53] where they were permanently separated from their families and communities. The illness itself - and the associated incarceration-disproportionately affected indigenous and other marginalized populations. A devastating loss of life occurred in these colonies, and it would seem easy to say that the medical profession would never allow such horrors to ever happen again in the world. However, in the form of serious mental illnesses and substance abuse, the medical profession is once again confronted with illnesses that share very similar characteristics and clearly result in marginalization and early death-even in the twenty-first century. Academic psychiatrists can learn these lessons of the past and teach trainees and the public about what is currently known about the mechanisms linking mental illness to early mortality. The leadership of academic psychiatrists is required to disrupt mechanisms that contribute to early deaths and to link these efforts with other professional groups and agencies to create better outcomes for individuals with mental illnesses.

\section{Compliance with Ethical Standards}

Disclosures On behalf of all authors, the corresponding author states that there is no conflict of interest.

\section{References}

1. Walker ER, McGee RE, Druss BG. Mortality in mental disorders and global disease burden implications: a systematic review and meta-analysis. JAMA Psychiat. 2015;72(4):334-41.

2. Vigo D, Thornicroft G, Atun R. Estimating the true global burden of mental illness. Lancet Psychiatry. 2016;3(2):171-8.

3. Ledford H. Medical research: if depression were cancer. Nature. 2014;515:182-4.

4. World Health Organization. Investing in mental health. World Health Organization. 2003. Available at: http:/www.who.int/ mental_health/media/investing_mnh.pdf. Accessed 26 Apr 2017

5. National Institutes of Health. Estimates of funding for various research, condition, and disease categories (RCDC). NIH RePORT. 2016. Available at: https://report.nih.gov/categorical_spending. aspx. Accessed 26 Apr 2017

6. Angermeyer MC, Dietrich S. Public beliefs about and attitudes toward people with mental illness: a review of population studies. Acta Psychiatr Scand. 2006;113(3):163-79.

7. Druss BG, Zhao L, Von Esenwein S, Morrato EH, Marcus SC. Understanding excess mortality in persons with mental illness: 17-year follow up of a nationally representative US survey. Med Care. 2011;49(6):599-604.

8. Parks J, Svendsen D, Singer P, Foti ME, eds. Morbidity and mortality in people with serious mental illness. National Association of State Mental Health Program Directors. 2006. Available at: https:// www.nasmhpd.org/sites/default/files/Mortality $\% 20$ and $\%$ 20Morbidity\%20Final\%20Report\%208.18.08.pdf. Accessed 26 Apr 2017

9. World Health Organization. Information sheet: premature death among people with severe mental disorders. World Health Organization. 2014. Available at: http://www.who.int/mental health/management/info_sheet.pdf. Accessed 26 Apr 2017

10. Center for Disease Control. 10 leading causes of death by age group, United States-2014. National Vital Statistics System, National Center for Health Statistics. Available at: http://www. cdc.gov/injury/images/lc-charts/leading_causes_of_death_age_ group 2014 1050w760h.gif. Accessed 26 Apr 2017

11. Weiner J, Richmond TS, Conigliaro J, Wiebe DJ. Military veteran mortality following a survived suicide attempt. BMC Public Health. 2011;11:374.

12. Hiroeh U, Appleby L, Mortesen PB, Dunn G. Death by homicide, suicide, and other unnatural causes in people with mental illness: a population-based study. Lancet. 2001;358(9299):2110-2.

13. Curtin SC, Warner M, Hedegaard H. Increase in suicide in the United States, 1999-2014. NCHS data brief, no 241. Hyattsville, MD: National Center for Health Statistics. 2016. Available at: https://www.cdc.gov/nchs/products/databriefs/db241.htm. Accessed 26 Apr 2017

14. Hartz SM, Pato CN, Medeiros H. Comorbidity of severe psychotic disorders with measures of substance use. JAMA Psychiat. 2014;71(3):248-54.

15. National Institute on Drug Abuse. Overdose death rates. National Institutes on Drug Abuse. 2017. Available at: https://www. drugabuse.gov/related-topics/trends-statistics/overdose-death-rates. Accessed 26 Apr 2017 
16. Case A, Deaton A. Rising morbidity and mortality in midlife among white non-Hispanic Americans in the 21st century. Proc Natl Acad Sci U S A. 2015;112(49):15078-83.

17. Centers for Disease Control and Prevention. Tobacco-related mortality. Centers for Disease Control and Prevention. 2016. Available at: https://www.cdc.gov/tobacco/data_statistics/fact_sheets/health effects/tobacco related mortality/. Accessed 26 Apr 2017.

18. Centers for Disease Control and Prevention. Tobacco use among adults with mental illness and substance use disorders. Centers for Disease Control and Prevention. 2017. Available at: https://www. cdc.gov/tobacco/disparities/mental-illness-substance-use/index. htm. Accessed 26 Apr 2017

19. Substance Abuse and Mental Health Services Administration. The NSDUH report: adults with mental illness or substance use disorder account for 40 percent of all cigarettes smoked. SAMHSA. 2013. Available at: https:/www.samhsa.gov/data/sites/default/files/spot104cigarettes-mental-illness-substance-use-disorder/spot104-cigarettesmental-illness-substance-use-disorder.pdf. Accessed 26 Apr 2017

20. Prochaska JJ, Hall SM, Bero LA. Tobacco use among individuals with schizophrenia: what role has the tobacco industry played? Schizophr Bull. 2008;34:555-67.

21. Prochaska JJ. Smoking and mental illness-breaking the link. NEJM. 2011;365:196-8.

22. Newcomer JW, Hennekens CH. Severe mental illness and risk of cardiovascular disease. JAMA. 2007;298:1794-5.

23. Correll CU, Frederickson AM, Kane JM, Manu P. Metabolic syndrome and the risk of coronary heart disease in 367 patients treated with second-generation antipsychotic drugs. J Clin Psychiatry. 2006;67(4):575-83.

24. Pacher P, Kecskemeti V. Cardiovascular side effects of new antidepressants and antipsychotics: new drugs, old concerns? Curr Pharm Des. 2004;10:2463-75.

25. De Hert M, Correll CU, Bobes J, et al. Physical illness in patients with severe mental disorders: prevalence impact of medications and disparities in health care. World Psychiatry. 2011;10(1):52-77.

26. Chesney E, Goodwin GM, Fazel S. Risks of all-cause and suicide mortality in mental disorders: a meta-review. World Psychiatry. 2014;13(2):153-60.

27. Crump C, Sundquist K, Winkleby MA, Sundquist J. Mental disorders and vulnerability to homicidal death: Swedish nationwide cohort study. BMJ. 2013;346:f557.

28. Rodway C, Flynn S, While D, et al. Patients with mental illness as victims of homicide: a national consecutive case series. Lancet Psychiatry. 2014;1(2):129-34.

29. Pridemore WA. The mortality penalty of incarceration: evidence from a population-based case-control study of working-age males. J Health Soc Behav. 2014;55(2):215-33.

30. James DJ, Glaze LE. Bureau of Justice Statistics Special Report: mental health problems of prison and jail inmates. U.S. Department of Justice. September 2006. Available at: https://www.bjs.gov/ content/pub/pdf/mhppji.pdf/. Accessed 28 Apr 2017

31. Galea S, Tracy M, Hoggatt K, DiMaggio C, Karpati A. Estimated deaths attributed to social factors in the United States. Am J Pub Health. 2011;101(8):1456-65.

32. Folsom DP, Hawthorne W, Lindamer L, et al. Prevalence and risk factors for homelessness and utilization of mental health services among 10,340 patients with serious mental illness in a large public mental health system. Am J Psychiatry. 2005;162(2):370-6.

33. Kessler RC, Akiskal HS, Ames M, et al. Prevalence and effects of mood disorders on work performance in a nationally representative sample of U.S. workers. Am J Psychiatry. 2006;163(9):1561-8.

34. Garfield RL, Zuvekas SH, Lave JR, Donohue JM. The impact of national health care reform on adults with severe mental disorders. Am J Psychiatry. 2011;168(5):486-94.

35. Lawrence D, Hancock KJ, Kisely S. The gap in life expectancy from preventable physical illness in psychiatric patients in
Western Australia: retrospective analysis of population based registers. BMJ. 2013;346:f2539.

36. McLearn KT, Minkovitz CS, Strobino DM, Marks E, Hou W. The timing of maternal depressive symptoms and mothers' parenting practices with young children: implications for pediatric practice. Pediatrics. 2006;118(1):e174-82.

37. Garner AS. Home visiting and the biology of toxic stress: opportunities to address early childhood adversity. Pediatrics. 2013;132(Suppl 2):S65-73.

38. Association of American Medical Colleges. 2016 physician specialty data report. AAMC Center for Workforce Studies. 2016. Available at: https://www.aamc.org/data/workforce/reports/ 457712/2016-specialty-databook.html. Accessed 26 Apr 2017

39. World Health Organization. Mental health atlas 2014. World Health Organization. 2015. Available at http://apps.who.int/iris/bitstream/ 10665/178879/1/9789241565011_eng.pdf?ua=1\&ua=1. Accessed 28 Apr 2017

40. Corrigan PW, Druss BG, Perlick DA. The impact of mental illness stigma on seeking and participating in mental health care. Pychol Sci Public Interest. 2014;15(2):37-70.

41. Diefenback DL, West MD. Television and attitudes toward mental health issues: cultivation analysis and the third-person effect. J Community Psychol. 2007;35(2):181-95.

42. Nordt C, Rossler W, Lauber C. Attitudes of mental health professional toward people with schizophrenia and major depression. Schizophr Bull. 2006;32(4):709-14.

43. Verhaeghe M, Bracke P. Associative stigma among mental health professionals: implications for professional and service user wellbeing. J Health Soc Behav. 2012;53(1):17-32.

44. Mental Health America. Mental health in America - access to care data. The State of Mental Health in America. Available at: http:// www.mentalhealthamerica.net/issues/mental-health-americaaccess-care-data. Accessed 26 Apr 2017

45. U.S. Department of Health and Human Services. President's HHS FY 2017 budget factsheet. HHS.gov. 2016. Available at: https:// www.hhs.gov/about/budget/fy2017/budget-factsheet/index.html. Accessed 26 Apr 2017

46. Kessler RC, Berglund P, Demler O, Jin R, Merikangas KR, Walters EE. Lifetime prevalence and age-of-onset distributions of DSM-IV disorders in the National Comorbidity Survey Replication. Arch Gen Psychiatry. 2005;62(6):593-602.

47. Wang PS, Berglund P, Olfson M. Failure and delay in initial treatment contact after first onset of mental disorders in the national comorbidity survey replication. Arch Gen Psychiatry. 2005;62(6):603-13.

48. Liu NH, Daumit GL, Dua T, et al. Excess mortality in persons with severe mental disorders: a multilevel intervention framework and priorities for clinical practice, policy and research agendas. World Psychiatry. 2017;16:30-40.

49. National Institute of Mental Health. Research domain criteria (RDoC). National Institutes of Health. 2017. Available at: https:// www.nimh.nih.gov/research-priorities/rdoc/index.shtml. Accessed 26 Apr 2017

50. National Alliance on Mental Illness. Road to recovery: employment and mental illness. NAMI. 2014. Available at: https://www.nami. org/About-NAMI/Publications-Reports/Public-Policy-Reports/ RoadtoRecovery.pdf. Accessed 26 Apr 2017

51. Minding Your Mind. Mental health programs. Available at http:// mindingyourmind.org/what-we-do/mental-health-educationprogram/. Accessed 4 May 2017

52. Association of American Medical Colleges. 2016 physician specialty data report. AAMC, 2016. Available at: https://www.aamc. org/data/workforce/reports/457712/2016-specialty-databook.html. Accessed 2 May 2017

53. Herman RDK. Out of sight, out of mind, out of power: leprosy, race, and colonization in Hawai'i. Hūlili: Multidiscip Res Hawaiian Well-Being. 2010;6:271-301. 